Original article

\title{
APPLICATION OF THE SCRUM FRAMEWORK ON PROJECTS IN IT SECTOR
}

\author{
Bojan Grebić ${ }^{1}$, Aleksandra Stojanović
}

${ }^{1}$ Serbian Armed Forces, Ministry of Defence Republic of Serbia

Received: 12 November 2021 Revised: 22 November 2021 Accepted: 5 December 2021

\section{INTRODUCTION}

Although traditional project management methods have worked well for decades, the rapid development of the information technology sector has made them less efficient nowadays compared to previous years. We find that the reason for this is the fact that they originated in a relatively stable environment that was not characterized by frequent and intense changes. However, modern business conditions have given rise to a new approach and to new project management methods which focus on flexibility, efficient change
Abstract: The aim of this paper is to reveal, examine and study the most important specifics of the Scrum framework application from a theoretical and practical aspect. The first section explains the basics of the agile approach, i.e. agile values and principles, with the idea of creating a starting point for understanding the Scrum framework and the environment in which it originated. Furthermore, the focus shifts to defining the role, significance and structure of the Scrum framework, with special emphasis on presenting Scrum roles, Scrum events and Scrum artefacts as completely new categories in project management unique to the Scrum framework. Starting with the importance and responsibility of each Scrum team member, followed by the duration, framework is presented to potential users so its ication can be better, easier and simpler both within the in the IT sector and in other sectors where the software solutions inects regarding the development of new software solutions in the Republic of Serbia are presented at the end of the paper, together with the conclusions concerning the prospects for further development and wider application of the Scrum framework in projects, regardless of their type,

Keywords: Scrum framework, agile approach, agile project management, IT projects, Scrum research.

implementation and early delivery of project products, i.e. they have led to the development of agile approach, Scrum framework and other methods, techniques and tools for project management.

\section{AGILE APPROACH}

Highsmith (2009) defines agility as "the ability to both create and respond to change in order to profit in a turbulent business environment, i.e. the ability to balance flexibility and stability", which leads us to the conclusion that the agile approach best reflects the essence of

Corresponding author. Email: grebic.b@gmail.com

ISSN 2560-4961 (online)

Copyright $\mathbb{C}$ 2021, The Authors. Published by IPMA Serbia.

This is an open access article under the CC BY-NC 4.0 license (https://creativecommons.org/licenses/bync/4.0/)

https://doi.org/10.18485/epmj.2021.11.2.4 
project management in today's business environment. Therefore, the agile approach should not be viewed only as a certain method or technique of project management, but as a completely new way of thinking, business management and decision making (Grebić, 2019).

One of the fundamental success factors of the agile approach lies in the optimal combination of elements of interactive and incremental project product development. The interactivity of the agile approach is reflected in the continuous communication between team members, stakeholders and customers, while the incremental nature of the agile approach is manifested in the creation of project products that can be used at the time of their delivery to customers (PMI, 2017).

\subsection{Agile Values}

The Agile Manifesto (Agile Alliance, 2001) defines four core values which represent the essential differences in relation to the traditional approach of project management, i.e. which emphasize elements that are preferable according to the agile approach, but are not explicit at any point and leave enough space for choosing an adequate way of working. Valuing individuals and interactions over processes and tools, working software over comprehensive documentation, customer collaboration over contract negotiation, and responding to change over following a plan, the agile approach enables project value creation that is better, faster and more complete, as well as project product delivery to customers, regardless of its complexity or required performance (Agile Alliance, 2001; Grebić, 2019).

\subsection{Agile Principles}

Agile principles are specific guidelines that should be followed in order to establish an agile atmosphere during the project, but also in order for the organisation to establish an agile work system. Having in mind the simplicity and practicality of agile principles, individuals and organisations achieve numerous positive effects through their application, from establishing a better team structure and communication that is more efficient, as well as earlier and better project product delivery, to satisfying the customers' needs and meeting the stakeholder requirements in a more adequate way. There are 12 agile principles and they point out the importance of direct communication and continuous cooperation, early and continuous project product delivery, as well as welcoming changes even in the late stages of the project. (Agile Alliance, 2001). Agile principles are also aimed at establishing self-organizing teams, respecting technical excellence, maintaining a constant working pace and providing support to motivated individuals (Agile Alliance, 2001).

\section{SCRUM FRAMEWORK}

The beginning of the Scrum framework development dates back to 1986 and to the article The New Product Development Game which was published in the Harvard Business Review. The authors of the article, Takeuchi and Nonaka, were among the first to notice the shortcomings of traditional project management methods, which due to their linear nature did not align with the new business conditions. However, although Takeuchi and Nonaka provided the foundations of the Scrum Framework and even influenced its name, the creators of the Scrum Framework are considered to be Ken Schwaber and Jeff Sutherland, who introduced it to the public in 1995.

Schwaber and Sutherland (2017) define Scrum as "a framework within which people can address complex problems while continuing to deliver products of the highest possible value productively and creatively". Defining Scrum in this way, they wanted to underline the possibility of using different techniques and tools together with Scrum processes, which is Scrum's great advantage over traditional methodologies that are linear and inflexible.

The Scrum framework aims at information transparency, direct communication and documentation availability, for continuous examination of the work method, project progress and the degree of project requirements fulfilment, as well as a high degree of adaptability that enables embracing change regardless of the stage of product development. Thus, we can conclude that the three fundamental pillars on which the Scrum framework rests are transparency, inspection 
and adaptation (Schwaber, \& Sutherland, 2017).

The development of the Scrum framework also introduces a number of innovations compared to the traditional approach to project management. First of all, the organisation of the project team has changed because Scrum does not recognize the function of a project manager, thus establishing new roles that have not existed before. Additionally, all activities within the project are now realised in equal time intervals and the approach to planning and completion of the project documentation has been modified. Also, how meetings are held is pre-defined, both in terms of time and the topic of the meeting. Therefore, in order to fully understand the Scrum framework, it is necessary to know the Scrum roles, events and artefacts.

\subsection{The Scrum Team}

The Scrum Team is a specific project organisation that requires the establishment of three completely new roles - Product Owner, Scrum Master and Development Team, all of whom have their own duties and responsibilities, but together are responsible for the success and goals of the project. The total number of team members, including the Product Owner and Scrum Master, should not exceed ten, which is optimal for maintaining self-organization and cross-functionality of the Scrum team, that is, for maintaining independence in choosing tools, techniques and tasks, on the one hand, and sharing knowledge and skills in order to strengthen team competence, on the other (Schwaber, \& Sutherland, 2017). As such, the Scrum team nurtures productivity, creativity and flexibility, regardless of the project's complexity and of the economic field in which the project is realised (Grebić, 2019; Schwaber, \& Sutherland, 2017).

Product Owner. The Product Owner is the person responsible for maximizing the value of project products that arise as a result of the Development Team's work (Scrum Study, 2017; Schwaber \& Sutherland, 2017). The Product Owner communicates stakeholder requirements to the Development Team by creating a Product Backlog, prioritising it and updating it according to the course of the project and changes in project requirements. That is why the Product Owner communicates with the Development Team on a daily basis and determines the tasks that need to be done or rejected, while determining the priority of their realisation. In essence, the responsibility for the success or failure of the project lies with the Product Owner because the correct interpretation of the stakeholder requirements and project value creation depends most on them as a representative of the stakeholders' interests in the project. (Scrum Study, 2017).

Regarding the Product Backlog, the Product Owner is responsible for defining and prioritising the Product Backlog items, approving changes and refining the Product Backlog, as well as ensuring comprehensibility, transparency and consistency of the Product Backlog, and thus optimising the value obtained by realising the Product Backlog items. Also, the Product Owner is responsible for defining the limits of the project - time, cost and resources; but also for monitoring financial indicators and controlling budget execution. (Cohn, 2010; Scrum Study, 2017).

Scrum Master. The Scrum Master is the person who promotes the Scrum framework during the project by helping everyone understand the theory, practice, values and principles of Scrum (Schwaber \& Sutherland, 2017). In essence, the Scrum Master is an expert in applying the Scrum framework qualified to guide all project participants and the organisation towards the proper application of the Scrum framework and agile approach in general, which is why this person is often called the administrator of the Scrum framework (Grebić, 2019; McDonald, n.d.). One Scrum Master role is usually established during a project, and sometimes it can be a member of the Development Team, especially if that person possesses technical knowledge. However, it is not recommended that this role be performed by the Product Owner (Cohn, 2010).

The Scrum Master provides the Development Team with an appropriate working environment by taking care of maintaining team independence, establishing adequate work dynamics and acquiring the necessary knowledge and skills, and thus contributes to a 
better understanding of the team's role in the project and in the organisation realising the project. (Scrum Study, 2017; Schwaber, \& Sutherland, 2017). It is important to highlight that the Scrum Master has absolutely no formal authority over other project participants, but has authority over the processes - this person is responsible for the successful establishment of Scrum events and the realisation of activities in accordance with the principles and values of this framework (Cohn, 2010; Scrum Study, 2017).

Development Team. The Development Team is a group of professionals who possess the knowledge necessary to create project products and whose work directly creates value in the project (Grebić, 2019; Schwaber, \& Sutherland, 2017). Within the Development Team there is no clear role distinction as is the case with Scrum Master and Product Owner, which does not exclude the importance of individuals for the team, but it is preferable to present the team as a united whole that completes tasks and solves the problems it faces, all with the aim of delivering the product to customers. To succeed in that, the Development Team members must have the full support of the organisation that realises the project, with the help of the Scrum Master. The Development Team selects methods, techniques and work tools independently, as well as selects the items of the Product Backlog to be realised during the Sprint, while the Scrum Master and the Product Owner must not directly influence their choice, but only point out its advantages and disadvantages. Given that the Development Team members know the product development process best and that they deliver product increments upon completion of the Sprint, it is clear why they have autonomy of choice.

The number of Development Team members varies depending on the complexity of the project, but should consist of a number of professionals sufficient to meet project requirements during the Sprint, and yet be small enough to be managed efficiently. (Cohn, 2010; Grebić, 2019; Scrum Study, 2017; Schwaber, \& Sutherland, 2017). Bearing this in mind, it is recommended that the Development Team have six to ten members in order to maintain efficient communication and work coordination (Scrum Study, 2017; Schwaber \& Sutherland, 2017).

\subsection{Scrum Events}

The Scrum framework prescribes the mandatory establishment of Scrum events in the project in order to minimise waste of time and avoid organising meetings that are not productive and useful enough to create value. Scrum events have a logical sequence and a limited duration that dictate the work dynamics and positively affect productivity and flexibility in project product development.

Sprint. The application of the Scrum framework implies that the project products are developed in equal time iterations called Sprint. Sprint is the core of Scrum and is defined as the time frame during which usable and functional versions of the project products are created, i.e. the time period in which potentially shippable product increments occur (Grebić, 2019; Mersino, 2015; Schwaber, \& Sutherland, 2017).

Essentially, during the Sprint, team members work on product development and on building product performance, thus meeting the stakeholder requirements and directing the project and organisation towards achieving the set goals. At the end of each Sprint, the Product Owner assesses the achievement of the Sprint Goal and accepts or does not accept the delivered product increments. If certain tasks are not completed during the Sprint, they can be rescheduled for the next Sprint, but only with the Product Owner's approval. At the end of the last Sprint and after the delivery of the final product to customers, the project can be considered complete.

The recommended duration of a Sprint is from one to four weeks, certainly no longer than one month (Schwaber, \& Sutherland, 2017). The duration of the Sprint remains constant throughout the project, thus achieving a uniform pace of work, reducing complexity, increasing flexibility, strengthening adaptability and reducing aversion to risks and changes. Changes in the duration of the Sprint are allowed only in the project's initial stages, when its duration has no impact on the team's work dynamics. 
Sprint Planning. Sprint Planning is a meeting where all Scrum team members participate together in planning the realisation of the next Sprint, each in their own domain. Sprint Planning is held at the beginning of each Sprint, and the recommended duration of this Scrum event is two hours for each Sprint week. (Scrum Study, 2017; Schwaber, \& Sutherland, 2017). The Scrum Master plays a key role in limiting the duration of the Sprint Planning event and seeks to maintain the focus of team members on planning the next Sprint. The most important inputs of the Sprint Planning event are the Product Backlog and the product increment created in the previous Sprint (Schwaber, \& Sutherland, 2017). The Product Owner does not have the right to directly influence the Development Team and the selection of the Product Backlog items that will be realised during the Sprint, but does so indirectly, through the prioritisation of tasks in the Product Backlog. The Development Team members independently assess the scope of tasks they will perform during the Sprint, because they know their own capacities best, after which they define a concrete plan for the realisation of these tasks, thus forming a Sprint Backlog for the following Sprint. Therefore, we can conclude that during the Sprint Planning event, the Product Backlog is refined and realisation of tasks for the following period is planned, which directly affects the time, costs and performance of the project products.

Daily Scrum. Daily Scrum is a fifteen-minute meeting of the Development Team members during which the realisation of tasks for the current day is planned (Schwaber, \& Sutherland, 2017). Daily Scrum is held every day at the same time, usually at the beginning of the day, and in the same place, usually in a room where the team has all the necessary information (Scrum Study, 2017). The responsibility for the realisation of the Daily Scrum meeting lies with the Scrum Master, who deals with the time limit and productivity of planning daily tasks.

The Daily Scrum event entails asking three key questions: what was done during the previous day, what can be achieved by the next meeting and what are the obstacles the team is facing (Schwaber, \& Sutherland, 2017). By answering these questions, the work done during the previous day is inspected and compared with the plan for that day, then the tasks and activities whose realisation is planned for that day are defined, and finally, the limitations and problems that slow down the execution of the planned tasks are stated. Problems are not resolved during the meeting in order not to waste time needed for planning, but after the meeting are addressed to the individuals responsible for solving them. The purpose of this approach is to optimise cooperation and improve team performance by creating conditions for efficient planning and realisation of activities according to the level of priority.

After the Daily Scrum meeting, the Development Team members continue working on the planned activities, but can independently organise other meetings according to their needs.

Sprint Review. Sprint Review is an event during which product increment inspection and acceptance occur, as well as Product Backlog refinement which is done in accordance with the team's proposals and stakeholder requirements (Scrum Study, 2017; Schwaber, \& Sutherland, 2017). The Sprint Review always takes place at the end of the Sprint and is limited to one hour for each Sprint week (Schwaber \& Sutherland, 2017). The Sprint Review is the responsibility of the Scrum Master, and the Development Team, Product Owner and project stakeholders participate in it. The presence of all project participants is mandatory because during the Sprint Review event the tasks performed during the Sprint are reviewed, the degree of the Sprint Goal achievement is assessed and new requirements and changes that are introduced in the Product Backlog are defined.

During the Sprint Review, all participants discuss the product increments delivered at the end of Sprint, while the Development Team provides additional explanations concerning product performance and highlights the problems it faces, and the Product Owner estimates the time needed to complete the project and negotiates the work that needs to be done during the next Sprint (Schwaber, \& Sutherland, 2017). The end result of the Sprint Review event is a revised Product Backlog that forms the basis for the next Sprint Planning (Schwaber, \& Sutherland, 2017). 
It is important to note that the Sprint Review demonstrates deviations from expected values in terms of time and cost, which helps define further steps towards improving productivity and profitability.

Sprint Retrospective. Sprint Retrospective is an event during which team members review their own work, discuss lessons learned from the previous Sprint and define measures for better work in the next Sprint. The Sprint Retrospective event takes place at the very end of the Sprint, right after the Sprint Review, and the recommended duration of the Sprint Retrospective event is 45 minutes for each Sprint week (Schwaber, \& Sutherland, 2017). The Scrum Master has the greatest responsibility for holding the Sprint Retrospective event where they act as an equal to the Development Team members with whom they discuss how to improve the Scrum framework application and other project management methods, techniques and tools. (Schwaber, \& Sutherland, 2017).

\subsection{Scrum Artefacts}

Product Backlog, Sprint Backlog and Product Increment are the core Scrum artefacts and they are visible results, i.e. the value of the entire team's work. The project usually begins with the creation of a Product Backlog, a priority list of project tasks and the characteristics of the product being developed, then continues with the creation of a Sprint Backlog and delivery of Product Increment, product improvement that is the sum of all previously created values, and finally, ends when stakeholder requirements are met and the final product is delivered to customers (Schwaber, \& Sutherland, 2017).

Product Backlog. The Product Backlog is a priority list of project requirements most often in the form of product characteristics and functionality or in the form of performance improvement and error correction. (Grebić, 2019; Schwaber, \& Sutherland, 2017). The Product Owner is fully responsible for creating, updating, refining and prioritising the Product Backlog, but consults the stakeholders and the Development Team members regarding these activities. (Cohn, 2010; Schwaber, \& Sutherland, 2017).
The Product Backlog is constantly changed according to the project's progress because new information about the product is adopted, that is, the performance of products that need to be created, tested or improved is boosted. Also, there is a continuous prioritisation of the Product Backlog items which involves determining the priority or order of realisation of project tasks. As a consequence of the Product Backlog prioritisation, there is a subtraction or addition of certain elements, that is, the up-to-dateness of the Product Backlog and compliance with changes in the project and in the project environment is ensured.

Sprint Backlog. The Sprint Backlog is the sum of selected Product Backlog items and the plan for their realisation during the next Sprint (Grebić, 2019; Schwaber, \& Sutherland, 2017). The Development Team members are responsible for creating and refining the Sprint Backlog on a daily basis, and thus for delivering visible product increments upon the end of the Sprint. Therefore, the Sprint Backlog is a kind of assessment made by the Development Team regarding the performance of the products that will be created during the Sprint and so it must be comprehensible, informative and accessible to all team members. In this context, the Sprint Backlog can be viewed as a source of information on the tasks planned for the next Sprint, but also as a basis for measuring progress during the Sprint. The Sprint Backlog is created at the Sprint Planning event, but is updated during each Daily Scrum in order to implement ongoing changes and adjust to team capacity. Thus, the Development Team members continuously identify the Sprint Backlog items that will be realised, removed or rescheduled, which is why the Sprint Backlog continues to evolve through Sprint (Schwaber, \& Sutherland, 2017). It is important to note that a new Sprint Backlog is created for each Sprint, as well as that the Sprint Review and Sprint Retrospective events indirectly influence its structure and manner of formation.

Product Increment. Product Increment is the sum of the Product Backlog items realised during the Sprint and the values created during all previous Sprints (Grebić, 2019; Schwaber, $\&$ Sutherland, 2017). The Development Team is responsible for creating the Product Increment and the Product Owner is the one 
who decides whether to accept the Product Increment upon the end of Sprint.

At the end of each Sprint, the Development Team must deliver visible, functional, and potentially shippable product increments that have some use value for customers. (Cohn, 2010; Grebić, 2019; Mersino, 2015; Schwaber, $\&$ Sutherland, 2017). Essentially, the Product Increment must meet at least the minimum defined acceptance criteria and reflect the performance required for a given level of project product development thus reducing the risk of delivering inadequate project products and of incurring large monetary losses.

\subsection{Good to Know}

About Scrum Roles. The Scrum framework is suitable for scaling within large projects and in these situations the roles of Chief Product Owner and Chief Scrum Master are established, and if the project is part of a program or portfolio, the roles of Program Product Owner and Program Scrum Master, i.e. Portfolio Product Owner and Portfolio Scrum Master must exist (Scrum Study, 2017). The event in which representatives of all Scrum teams involved in the project's realisation participate is called the Scrum of Scrums (Scrum Study, 2017). Also, all listed roles, including Development Team members, are considered core roles, while all other participants (e.g. stakeholders, clients, customers, suppliers) are non-core roles (Scrum Study, 2017).

About Scrum Events. Scrum Events are designed to improve project processes, primarily project activity planning, value creation, change management and risk management. By combining Scrum Events with an equal distribution of responsibilities in the project, the Scrum framework contributes to relieving the traditional role of project manager, enabling earlier delivery of project products, reducing overall risk exposure and nurturing a culture of embracing change (Grebić, 2019).

About Scrum Artefacts. The Scrum framework is modular and allows the formulation of artefacts beyond the abovementioned core artefacts, the most important of which are (Scrum Study, 2017):
- Product Vision - a long-term mission that ensures the continuous focus of all project participants on a common goal;

- User Story - a complete set of project requirements that indicates what needs to be done in order for the project products to meet customer expectations;

- Epic - Complex groups of project requirements consisting of several User Stories;

- Sprint Goal - a unique goal achieved by realising development work and delivering product increment at the end of the Sprint;

- Acceptance Criteria - criteria for assessing the degree to which defined requirements are met.

\section{RESEARCH ON THE APPLICATION OF THE SCRUM FRAMEWORK}

Research called The Application of Scrum framework in the development of new software solutions was conducted in October and November of 2020 with the aim to examine the level of knowledge and proper application of the Scrum framework and the agile approach, to determine the role of education and certification in the application of the Scrum framework, as well as to enable research participants and organisations to which they belong to perform self-assessment of their knowledge of the Scrum framework.

\subsection{Research Participants Structure}

Representatives of nine companies and enterprises operating within the borders of the Republic of Serbia, engaged in the development of software solutions, system administration, IT project management, general management, and the like, took part in the research.

The results showed that the staff involved in the development of new software solutions is young because as many as $79 \%$ of respondents are under 35 years old. The work experience of the respondents is in line with their age and most of them have been working in the IT sector for two to four years $(28.9 \%)$, followed by persons who have been working in the IT sector for less than two years $(23.7 \%)$. The 
other half of the respondents have been employed in the IT sector for more than four years, and the detailed structure of work experience is shown in Figure 1.

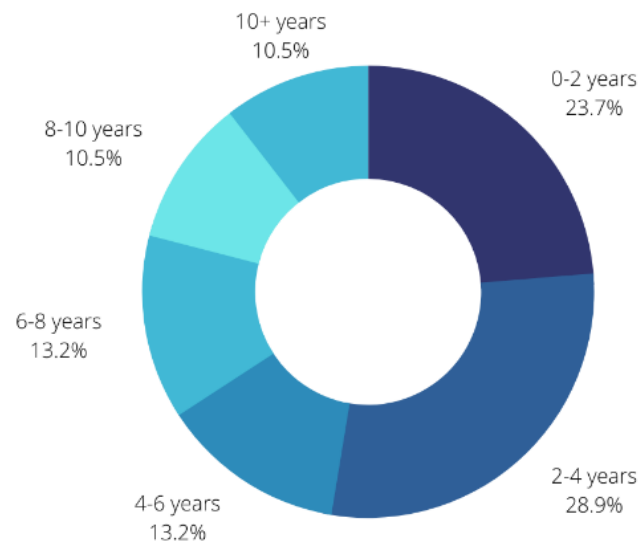

Figure 1: The work experience of the respondents (in percent).

When it comes to the operations of companies whose representatives participated in the survey, the majority were those companies which have been operating in the Republic of Serbia for six to nine years (34.2\%), followed by companies that have been operating for less than three years $(26.3 \%)$ and those which have done so for three to six years $(15.8 \%)$.

\subsection{Scrum Framework and Agile Approach Application}

Research participants answered ten questions about the application of the Scrum framework and the agile approach using a numerical scale from 1 to 5, with the following meaning: $1-$ Never; 2 - Hardly Ever; 3 - Not Sure; 4 Almost Always; 5 - Always.

The results of the research showed that $44.7 \%$ of respondents always use an agile approach, $23.9 \%$ of respondents almost always apply it, and only $7.9 \%$ of respondents never apply an agile approach. (See Q1, Figure 2). When it comes to the Scrum framework, the situation is almost identical because $7.9 \%$ of respondents never use Scrum, but $34.2 \%$ of respondents almost always use Scrum and $26.3 \%$ of respondents always use Scrum (See Q2, Figure 2). Also, the vast majority of respondents believe that the application of the Scrum framework significantly facilitates their work (See Q3, Figure 2), as well as that they work in environments that are largely not averse to the Scrum framework. (See Q4, Figure 2).

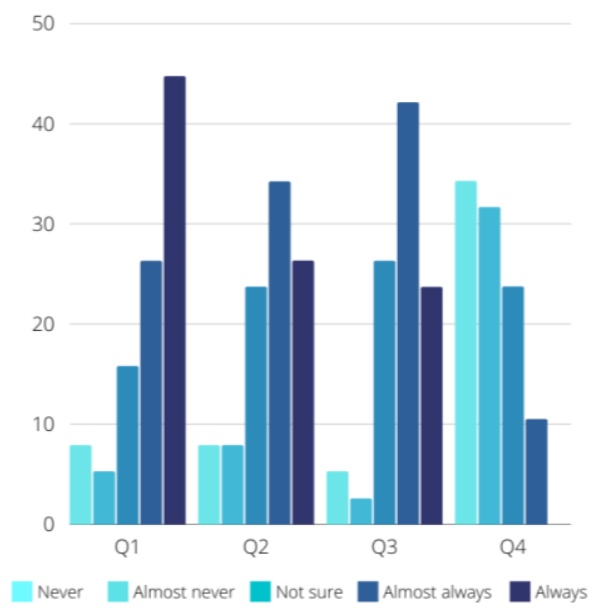

Figure 2: The frequency of the Scrum framework and agile approach application (in percent).

However, none of the participants in the survey believes that the organization to which they belong fully respects the principles and values of the Scrum framework, but a high $47.4 \%$ of respondents confirm that they almost always respect the prescribed principles and values (See Q5, Figure 3). On the other hand, more than half of the participants almost always or always establish the prescribed Scrum roles (27\% for both situations) (See Q6, Figure 3), but the rules regarding the realization of events are followed to a lesser extent, because one fifth of the participants never or hardly ever organise events in accordance with the Scrum framework (See Q7, Figure 3).

Also, the results showed that more than $76 \%$ of the participants never or hardly ever had problems understanding the Scrum framework (See Q8, Figure 3), but that they are still largely unsure whether they would prefer to use Scrum compared to other methodologies $(42.1 \%)$, that is, to use Scrum rather than other methodologies almost always (42.1\%) (See Q9, Figure 3). It is important to note that the participants in the survey believe that their HR sector does not contribute enough to the staff training in the domain of Scrum framework (See Q10, Figure 3). 


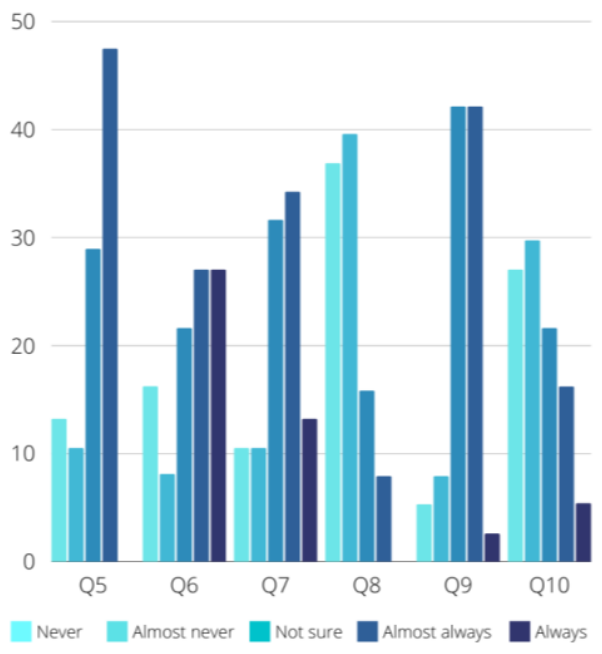

Figure 3: Different aspects of the Scrum framework application (in percent)

\subsection{Scrum Framework Knowledge Self- assessment}

Research participants answered six questions regarding their knowledge of the Scrum framework, on a numerical scale from 1 to 5 , with the following meaning: 1 - Extremely poor; 2 - Poor; 3 - Good; 4 - Very good; 5 Excellent.

The results showed that more than $65 \%$ of the respondents think they have either a very good or an excellent grasp of the Scrum framework (See Q11, Figure 4), and that the knowledge of the Scrum framework in the organization to which they belong is on a remarkably high level. (See Q12, Figure 4). Also, the respondents rated the Scrum framework from their point of view as extremely effective (73.7\% affirmative answers) (See Q13, Figure 4), comprehensible $(71.1 \%$ affirmative answers) (See Q14, Figure 4), applicable (65.8\% affirmative answers) (See Q15, Figure 4) and useful (76.4\% affirmative answers) (See Q16, Figure 4).

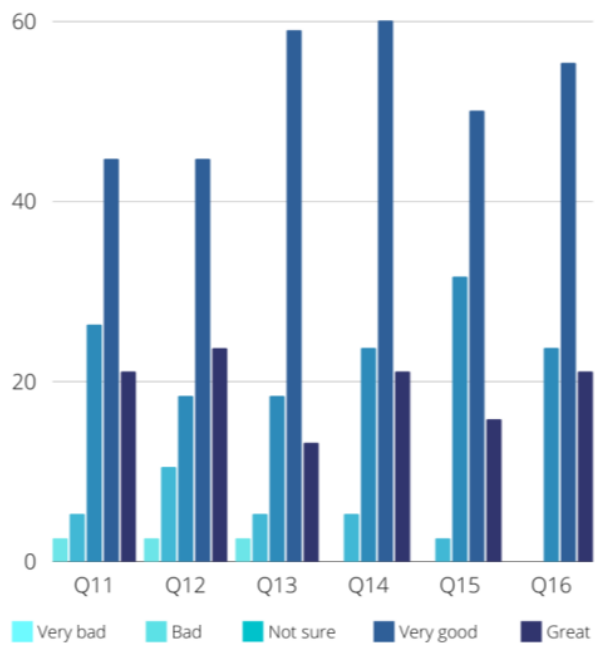

Figure 4: Scrum framework Knowledge Selfassesment and Scrum framework usefulness (in percent)

\subsection{Education and Certification in Scrum Framework Application}

The results of the research on education and certification in Scrum framework application showed that slightly more than half of the research participants did not complete any kind of education in this domain (52.6\%) (See Q17, Figure 5), and that $51.3 \%$ of organisations and employers do not organize training in Scrum framework application (See Q18, Figure 5). Accordingly, as many as $76.3 \%$ of respondents do not have any certificate in general Scrum framework knowledge (See Q19, Figure 5), and only $26.3 \%$ of respondents are certified for one of the core Scrum roles (See Q20, Figure 5). Among the certified respondents, $36.4 \%$ are Scrum Masters, $63.6 \%$ are Development Team members and no one is certified for the role of Product Owner (See Q21, Figure 5). Finally, it is important to note that $63.2 \%$ of respondents prefer foreign education centres (e.g. Scrum.org, Scrum Alliance) to domestic education centres (See Q22, Figure 5). 


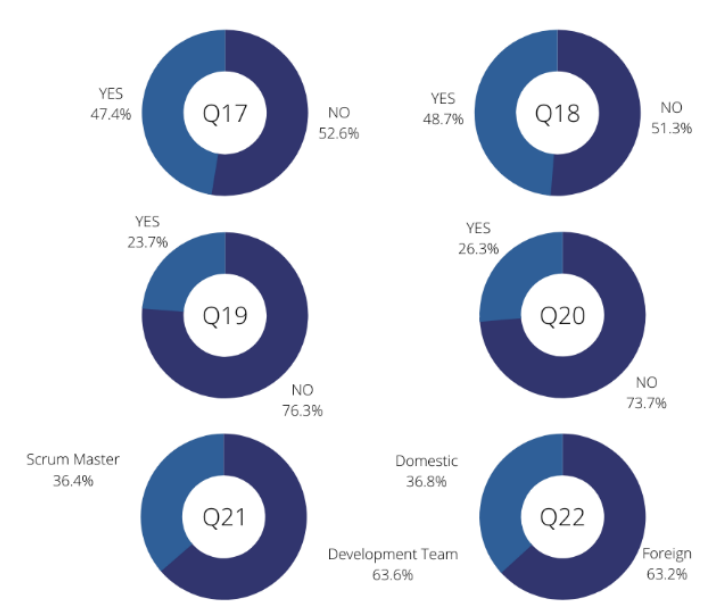

Figure 5: Scrum framework education and certfication (in percent)

\section{CONCLUSION}

The most valuable advantage of the Scrum framework is the continuous process improvement entailing communication and cooperation that are more efficient, both within the team and with stakeholders, increased team productivity and better distribution of responsibilities, as well as faster and better delivery of project products to customers. Moreover, it is worthy of note that the Scrum framework integrates the risk and change management system into everyday activities, further simplifying planning and project documentation, but also reducing potential losses and making better use of potential opportunities. Therefore, we can conclude that the application of the Scrum framework is constantly improving project products and processes as well as all the tools, methods and techniques used within the project.

These research results have once again confirmed the high degree of Scrum framework's success in the practice of developing new software solutions, because the participants described the Scrum framework as a useful, practical and simple approach that facilitates the achievement of goals. That is why the Scrum framework is one of the first choices of organisations and employees when realising projects in the information technology sector, but also in other sectors that require an agile, adaptive and iterative approach. However, in addition to all the positive findings, the research also pointed out the existence of one negative phenomenon - organisations should pay much more attention to the education and certification of staff regarding the application of the Scrum framework. Having in mind all the above, we come to the conclusion that the Scrum framework will be applied even more in the near future, but that it will also continue evolving in accordance with changes in the environment that dictate work dynamics and create general business conditions.

\section{REFERENCES}

Agile Alliance. (2001). The Agile Manifesto. USA: Author.

Augustine, S. (2005). Managing Agile Projects. New Jersey: Prentice Hall.

Cohn, M. (2005). Agile Estimating and Planning. New Jersey: Prentice Hall.

Cohn, M. (2010). Succeeding with Agile. Boston: Pearson Education Inc.

Grebić, B. (2019). Traditional vs Agile Project Management in the Service Sector. European Project Management Journal 9(2), pp. 55-63. https://doi.org/10.18485/epmj.2019.9.2.6

Highsmith, J. (2009). Agile Project Management. Boston: Addison-Wesley.

International Project Management Association. (2015). Individual Competence Baseline in Agile World. Zurich, Switzerland: Author.

Layton, M. (2012). Agile Project Management. New Jersey: John Wiley\&Sons, Inc.

Mersino, A. (2015). Agile Project Management: A Nuts and Bolts Guide to Success. USA: Vitality.

Pries, K. (2014). Scrum Project Management. USA: Taylor \& Francis Group.

Project Management Institute. (2017). Agile Practice Guide. Pennsylvania: Author.

Schmidt, T. (2009). Strategic Project Management Made Simple. New Jersey: John Wiley\&Sons, Inc.

Schwaber, K., \& Sutherland, J. (2017). The Scrum Guide. USA: Creative Commons.

Schwaber, K. (1995). Scrum Development Process. USA: Advanced Development Methods.

Scrum Study. (2017). A Guide to Scrum Body of Knowledge, Third Edition. USA: Author.

Takeuchi, H., \& Nonaka, I. (1986). The New New Product Development Game. Harward Business Review, JanuaryFebruary 1986, pp. 137-146. 